\title{
Long-Term Outcomes after Endoscopic Treatment of Gastric Gastrointestinal Stromal Tumor
}

\author{
Jong-Jae Park \\ Division of Gastroenterology, Department of Internal Medicine, Korea University Guro Hospital, Korea University College of Medicine, Seoul, \\ Korea
}

Endoscopic resection of gastric subepithelial tumors (SETs) has several advantages over biopsy techniques, such as superior diagnostic yield and definite diagnosis. Removal of gastric SETs and histopathologic confirmation should be considered whenever gastric SETs are highly suspected to have malignant potential such as gastrointestinal stromal tumor (GIST) or neuroendocrine tumor. According to our clinical experience, we suggest that endoscopic resection of gastric SETs is feasible for GISTs less than $3.0 \mathrm{~cm}$ without positive endoscopic ultrasonography findings or for hypoechoic SETs less than $3.0 \mathrm{~cm}$. However, serious complications such as macroperforation may occur during endoscopic resection, and this procedure is highly dependent on endoscopists' skills. We recently reported the longterm clinical outcomes of endoscopic resection of gastric GIST, which showed a relatively low recurrence rate (2.2\%) during long-term follow-up (46.0 \pm 28.5 months) despite the low R0 resection rate (25.0\%). We suggest that endoscopic surveillance might be possible without additional surgical resection in completely resected GISTs without residual tumor confirmed to be lower risk, even if they show an R1 resection margin. Clin Endosc 2016;49:232-234

Key Words: Subepithelial tumor; Gastrointestinal stromal tumors; Endoscopy

\section{INTRODUCTION}

Subepithelial tumors (SETs) in the stomach are usually found incidentally during endoscopic examinations. ${ }^{1}$ Most gastric SETs do not cause symptoms and were formerly considered to have a benign nature, such as lipomas, inflammatory fibroid polyps, or several neural origin tumors (i.e., schwannomas). ${ }^{2}$ However, several gastric SETs have malignant potential, especially when they originate from the muscularis propria (MP) layer, such as gastrointestinal stromal tumors (GISTs), neuroendocrine tumors (NETs), glomus tumors, and even metastastic tumors. ${ }^{3}$ Thus, removal of gastric SETs and histopathologic confirmation are required when GIST or NET

Received: March 17, 2016 Accepted: April 18, 2016

Correspondence: Jong-Jae Park

Division of Gastroenterology, Department of Internal Medicine, Korea University Guro Hospital, Korea University College of Medicine, 148 Gurodong-ro, Gurogu, Seoul 08308, Korea

Tel: +82-2-2626-1027, Fax: +82-2-2626-1038, E-mail: gi7pjj@korea.ac.kr

cc This is an Open Access article distributed under the terms of the Creative Commons Attribution Non-Commercial License (http://creativecommons.org/ licenses/by-nc/3.0) which permits unrestricted non-commercial use, distribution, and reproduction in any medium, provided the original work is properly cited. is highly suspected.

In this review, we summarize the critical points when planning endoscopic resection of gastric SETs as well as the longterm clinical outcomes of endoscopic resection of gastric GIST.

\section{CONSIDERATIONS FOR ENDOSCOPIC RESECTION OF GASTRIC SETs}

Endoscopic resection of gastric SETs has several advantages over biopsy techniques. First, diagnostic yield can be improved by obtaining whole SET tissue; thus, endoscopists can avoid frequent re-examination. Second, physicians are able to confidently provide a therapeutic plan to patients according to definite diagnosis; thus, reassuring patients and reducing their anxiety. Third, insurance-related conflicts can be avoided. Unfortunately, neither strict guidelines nor widespread acceptance for endoscopic resection as the treatment for gastric SETs have yet been established. We cautiously suggest indications for endoscopic resection based on our clinical ex- 
Table 1. Results of Endoscopic Treatment of Subepithelial Tumor in the Upper Gastrointestinal Tract

\begin{tabular}{|c|c|c|c|c|c|c|}
\hline Study & Method & $\begin{array}{l}\text { No. of case, total } \\
\text { (E/S/D) }\end{array}$ & $\begin{array}{c}\text { Layer of origin, } \\
\mathrm{mm} / \mathrm{sm} / \mathrm{mp}\end{array}$ & $\begin{array}{l}\text { Dx., GIST/ } \\
\text { other }\end{array}$ & $\begin{array}{c}\text { Complete resection, } \\
n(\%)\end{array}$ & $\begin{array}{c}\text { Perforation, } n \\
\text { (\%) }\end{array}$ \\
\hline Li et al. $(2013)^{6}$ & ESD & $11(0 / 11 / 0)$ & $0 / 0 / 11$ & $8 / 3$ & $10 / 11(91)$ & $3 / 11(27)$ \\
\hline Chun et al. $(2013)^{7}$ & ESD & $35(0 / 35 / 0)$ & $0 / 0 / 35$ & $10 / 25$ & $26 / 35(74)$ & $2 / 35(5.7)$ \\
\hline Lee et al. $(2006)^{8}$ & ESD/EMD & $12(0 / 12 / 0)$ & $0 / 0 / 12$ & $8 / 4$ & $9 / 12(75)$ & $0 / 12(0)$ \\
\hline Park et al. $(2004)^{9}$ & EE-I & $15(5 / 10 / 0)$ & $1 / 2 / 11$ & $4 / 11$ & $14 / 15(93)$ & $1 / 15(7)$ \\
\hline Goessl et al. $(2007)^{10}$ & EE-I & $3(0 / 3 / 0)$ & $0 / 0 / 3$ & $3 / 0$ & $3 / 3(100)$ & $0 / 3(0)$ \\
\hline Sun et al. $(2004)^{11}$ & Band ligation & $64(50 / 12 / 2)$ & $0 / 0 / 64$ & $0 / 64$ & 61/64 (95) & $0 / 64(0)$ \\
\hline Hoteya et al. $(2009)^{12}$ & ESD & $9(0 / 9 / 0)$ & mm or sm only & $1 / 8$ & $9 / 9(100)$ & $0 / 9(0)$ \\
\hline Białek et al. $(2012)^{13}$ & ESD & $37(0 / 37 / 0)$ & $0 / 15 / 22$ & $17 / 20$ & $30 / 37(81)$ & $2 / 37(5.4)$ \\
\hline Catalano et al. $(2013)^{14}$ & ESD & $20(0 / 20 / 0)$ & $0 / 17 / 3$ & $10 / 10$ & $18 / 20(90)$ & $3 / 20(15.0)$ \\
\hline He et al. $(2013)^{16}$ & ESD & $144(0 / 144 / 0)$ & $0 / 0 / 144$ & $89 / 55$ & $134 / 144(92)$ & 21/144 (14) \\
\hline Zhang et al. $(2013)^{17}$ & ESD & $18(0 / 18 / 0)$ & $0 / 0 / 18$ & $13 / 5$ & $17 / 18(94)$ & 2/18 (11) \\
\hline
\end{tabular}

$\mathrm{E} / \mathrm{S} / \mathrm{D}$, esophagus/stomach/duodenum; mm/sm/mp, muscularis mucosa/submucosa/muscularis propria; Dx., diagnosis; GIST, gastrointestinal stromal tumor; ESD, endoscopic submucosal dissection; EMD, endoscopic muscular dissection; EE-I, en bloc enucleation with ITknife.

periences as follows: GISTs less than $3.0 \mathrm{~cm}$ without positive endoscopic ultrasonography (EUS) findings (i.e., irregular borders, cystic space, ulceration, echogenic foci, and heterogeneity) or hypoechoic SETs less than $3.0 \mathrm{~cm}$. However, there are several limitations in applying these indications. First, the tumor should be smaller than 3.0 to $4.0 \mathrm{~cm}$, even though the exact cut-off limit remains controversial. If the tumor is larger than this limit, endoscopic resection might be technically unavailable or cause serious complications including macroperforation. Second, the endoscopic procedure is operator-dependent, because the techniques mentioned above require highly advanced skills and sufficient clinical experience. Third, only limited studies including small numbers of patients and shortterm follow-up periods have been published and are thus subject to selection biases. Table 1 summarizes procedure-related outcomes of endoscopic resection of SETs in the upper gastrointestinal tract (UGIT).

Another important issue concerning endoscopic resection is post-procedural use of imatinib. Recent guidelines from the National Comprehensive Cancer Network state that if GISTs are completely resected (including R1 resection), adjuvant therapy with imatinib can be considered, especially for patients with a significant high risk of recurrence (intermediate or high risk by recent World Health Organization classifications). ${ }^{4}$ However, imatinib therapy followed by endoscopic resection is neither approved nor covered by the national health insurance system in Korea, and guidelines from the Korean GIST Study Group suggest that complete en bloc resection with negative margins should be performed regardless of tumor size; therefore, even if the tumor is small, endoscopic shell-out procedure or enucleation should be avoided if GIST is suspected. ${ }^{5}$ Further discussion and opinions should be based on clinical outcomes and long-term follow-up data of endoscopic procedures.

\section{LONG-TERM CLINICAL OUTCOMES OF ENDOSCOPIC TREATMENT OF GASTRIC GIST}

As technical skills have advanced and novel endoscopic procedures have been developed, complete en bloc endoscopic resection of gastric SETs has been reported. ${ }^{6-17}$ However, they included only a small number of gastric GISTs, and their longterm follow-up results have not yet been reported. Recent studies have reported no recurrence of gastric GISTs resected by endoscopic procedure; however, their follow-up periods were relatively short, ranging from 1 to 2 years. ${ }^{16,17}$ Here, we show our clinical outcomes of endoscopic resection for gastric GISTs. ${ }^{18}$ A total of 249 patients with SET in the UGIT underwent endoscopic resection in our hospital; among them, 89 cases were confirmed as gastric GIST by histopathologic examination. The most common site of the gastric GISTs was the gastric body (43.3\%), followed by the cardia (22.2\%) and fundus $(21.1 \%)$. The mean tumor size was $2.3 \pm 1.2 \mathrm{~cm}$, and most were considered to have originated from the MP layer (64.4\%) based on pre-procedural EUS findings. Most of the tumors were resected by endoscopic submucosal dissection (80.0\%), followed by submucosal tunneling endoscopic resection (8.9\%), and two cases (2.2\%) by endoscopic full-thickness resection. The complication rate was $14.4 \%$, including microand macroperforation $(5.6 \% / 4.4 \%$, respectively) and major 
bleeding (2.2\%). The recurrence rate was relatively low (2.2\%) during the long-term follow-up period (46.0 \pm 28.5 months) despite the low $\mathrm{R} 0$ resection rate $(25.0 \%)$ and did not differ significantly from that of surgically resected gastric GIST (5.0\%). This comparable recurrence rate may be explained by the fact that most of the gastric GISTs in the endoscopic resection group had smaller sizes and low mitotic index counts $(<5 /$ high power field, $84.4 \%$ ), which consequently corresponded to very low (50.0\%) and low (31.1\%) risk. Indeed, if a GIST is completely resected without residual tumor in an endoscopic view and is classified as lower risk by histopathological evaluation, the endoscopic procedure may be an alternative choice for optimal treatment of GIST in the UGIT, even with R1 resection margins. Further evaluation with large-scale prospective studies is needed to clarify this issue.

\section{CONCLUSIONS}

Endoscopic resection of gastric GIST is increasingly used for tissue diagnosis and treatment, and is expected to be a substitute for surgical resection in selected cases. Endoscopic resection is a feasible and effective alternative therapeutic modality for lower risk gastric GIST with acceptable long-term follow-up results.

Conflicts of Interest

The author has no financial conflicts of interest.

\section{REFERENCES}

1. Hedenbro JL, Ekelund M, Wetterberg P. Endoscopic diagnosis of submucosal gastric lesions. The results after routine endoscopy. Surg Endosc 1991;5:20-23.

2. Jeong ID, Jung SW, Bang SJ, Shin JW, Park NH, Kim do H. Endoscopic enucleation for gastric subepithelial tumors originating in the muscularis propria layer. Surg Endosc 2011;25:468-474.

3. Hwang JH, Rulyak SD, Kimmey MB; American Gastroenterological Association Institute. American Gastroenterological Association Institute technical review on the management of gastric subepithelial masses.
Gastroenterology 2006;130:2217-2228

4. von Mehren M, Randall RL, Benjamin RS, et al. Gastrointestinal stromal tumors, version 2.2014. J Natl Compr Canc Netw 2014;12:853-862.

5. Kang YK, Kim KM, Sohn T, et al. Clinical practice guideline for accurate diagnosis and effective treatment of gastrointestinal stromal tumor in Korea. J Korean Med Sci 2010;25:1543-1552.

6. Li L, Wang F, Wu B, Wang Q, Wang C, Liu J. Endoscopic submucosal dissection of gastric fundus subepithelial tumors originating from the muscularis propria. Exp Ther Med 2013;6:391-395.

7. Chun SY, Kim KO, Park DS, et al. Endoscopic submucosal dissection as a treatment for gastric subepithelial tumors that originate from the muscularis propria layer: a preliminary analysis of appropriate indications. Surg Endosc 2013;27:3271-3279.

8. Lee IL, Lin PY, Tung SY, Shen CH, Wei KL, Wu CS. Endoscopic submucosal dissection for the treatment of intraluminal gastric subepithelial tumors originating from the muscularis propria layer. Endoscopy 2006;38:1024-1028.

9. Park YS, Park SW, Kim TI, et al. Endoscopic enucleation of upper-GI submucosal tumors by using an insulated-tip electrosurgical knife. Gastrointest Endosc 2004;59:409-415.

10. Goessl C, Hempfling W, Hoppe B, Stolte M, Frank N. Endoscopic enucleation of small gastrointestinal stromal tumors from the stomach. Endoscopy 2007;39 Suppl 1:E308.

11. Sun S, Jin Y, Chang G, Wang C, Li X, Wang Z. Endoscopic band ligation without electrosurgery: a new technique for excision of small upper-GI leiomyoma. Gastrointest Endosc 2004;60:218-222.

12. Hoteya S, Iizuka T, Kikuchi D, Yahagi N. Endoscopic submucosal dissection for gastric submucosal tumor, endoscopic sub-tumoral dissection. Dig Endosc 2009;21:266-269.

13. Białek A, Wiechowska-Kozłowska A, Pertkiewicz J, et al. Endoscopic submucosal dissection for treatment of gastric subepithelial tumors (with video). Gastrointest Endosc 2012;75:276-286

14. Catalano F, Rodella L, Lombardo F, et al. Endoscopic submucosal dissection in the treatment of gastric submucosal tumors: results from a retrospective cohort study. Gastric Cancer 2013;16:563-570.

15. Kobara H, Mori H, Rafiq K, et al. Indications of endoscopic submucosal dissection for symptomatic benign gastrointestinal subepithelial or carcinoid tumors originating in the submucosa. Mol Clin Oncol 2013;1:1002-1008.

16. He Z, Sun C, Wang J, et al. Efficacy and safety of endoscopic submucosal dissection in treating gastric subepithelial tumors originating in the muscularis propria layer: a single-center study of 144 cases. Scand J Gastroenterol 2013;48:1466-1473.

17. Zhang S, Chao GQ, Li M, Ni GB, Lv B. Endoscopic submucosal dissection for treatment of gastric submucosal tumors originating from the muscularis propria layer. Dig Dis Sci 2013;58:1710-1716.

18. Joo MK, Park JJ, Kim H, et al. Endoscopic versus surgical resection of GI stromal tumors in the upper GI tract. Gastrointest Endosc 2016;83:318326. 